\title{
The Capacitive Behaviors of Manganese Dioxide Thin-Film Electrochemical Capacitor Prototypes
}

\author{
Suh Cem Pang, Boon Hong Wee, and Suk Fun Chin \\ Department of Chemistry, Faculty of Resource Science and Technology, Universiti Malaysia Sarawak, Kota Samarahan 94300, \\ Sarawak, Malaysia \\ Correspondence should be addressed to Suh Cem Pang, suhcem@gmail.com
}

Received 31 May 2011; Revised 21 July 2011; Accepted 18 August 2011

Academic Editor: Kenneth I. Ozoemena

Copyright ( $\odot 2011$ Suh Cem Pang et al. This is an open access article distributed under the Creative Commons Attribution License, which permits unrestricted use, distribution, and reproduction in any medium, provided the original work is properly cited.

We have documented the fabrication of manganese dioxide $\left(\mathrm{MnO}_{2}\right)$ thin-film electrochemical capacitor (EC) prototypes with dual-planar electrode configuration. These EC prototypes exhibited good capacitive behaviors in mild $\mathrm{Na}_{2} \mathrm{SO}_{4}$ aqueous electrolyte. Enhanced capacitive behaviors of EC prototypes were observed upon prolonged voltammetric cycling which could be associated with microstructural transformation of $\mathrm{MnO}_{2}$ thin-film electrodes from densely packed plate-like to irregular petal-like surface morphology. Effects of voltammetric scan rates, prolonged voltammetric cycling, electrolyte composition, and electrolyte concentration on the surface morphology of $\mathrm{MnO}_{2}$ thin-film electrodes, and associated capacitive behaviors of $\mathrm{MnO}_{2}$ thin-film EC prototypes were investigated by cyclic voltammetry (CV), electrochemical impedance spectroscopy (EIS), and galvanostatic charge/discharge (GCD) techniques. Results of both CV and EIS indicated that thin-film $\mathrm{MnO}_{2}$ EC prototypes exhibited the highest specific capacitance of $327 \mathrm{~F} / \mathrm{g}$ in $0.2 \mathrm{M} \mathrm{Na}_{2} \mathrm{SO}_{4}$ aqueous electrolyte. Being environmentally benign and cheap, $\mathrm{MnO}_{2}$ thinfilm electrochemical capacitors have high potential utility as pulsed power sources, as well as load-leveling functions in various consumer electronic devices.

\section{Introduction}

The phenomenal increase in demands for electronic devices, power tools, and energy-intensive device applications necessitate the continual development of new generation energystorage systems of high rate capability and performances. Energy-storage devices particularly pseudocapacitive electrochemical capacitors (ECs) fabricated using various nanoparticulate transition metal oxides have gained increasing interest among research scientists worldwide due to their high energy and power densities. Among them, manganese dioxide- $\left(\mathrm{MnO}_{2}-\right)$ based electrodes have been reported to exhibit high specific capacitance which ranged from 130 to $700 \mathrm{~F} / \mathrm{g}$ in mild aqueous electrolytes [1-3]. However, these capacitance values are still substantially lower than the theoretical value of $1,380 \mathrm{~F} / \mathrm{g}$ which corresponds to the complete reduction of $\mathrm{Mn}^{4+}$ to $\mathrm{Mn}^{3+}$. Low utilization of bulk $\mathrm{MnO}_{2}$ electroactive material for electrical energy storage could be mainly attributed to microstructural factors associated with the electroactive material concerned. As such, microstructural control at the nanoscale has been one of the major focuses in the development of novel electroactive materials that exhibit both high energy and power densities. Electroactive materials of desired pore size distribution, microstructure, composition, particles size, as well as electrochemically active functional groups could be precisely architectured at nanoscale dimension [4]. However, the manufacturing of such electroactive materials required rigorous and expensive processing steps, and hence economically not feasible for commercial energy storage applications. To date, various types of electroactive materials such as nanostructured $\mathrm{MnO}_{2}$ of nanofibers [5, 6], nanowires [7], sea urchin-like and clew-like shapes [8], carambola-like nanoflakes [9], and nanorods [10] have been synthesized by various approaches. However, none of these nanostructured $\mathrm{MnO}_{2}$ materials could achieve the level of electrochemical performances close to the theoretical specific capacitance value of $\mathrm{MnO}_{2}$.

The microstructure and surface morphology of $\mathrm{MnO}_{2}$ thin films are of particular interest since they influence the 
capacitive behaviors of $\mathrm{MnO}_{2}$ EC prototypes. This study has focused on elucidating factors that affect the capacitive behaviors of $\mathrm{MnO}_{2}$-based thin-film EC prototypes. Nanostructured $\mathrm{MnO}_{2}$ thin films were deposited directly onto nickel-coated poly(ethylene terephthalate) (Ni-PET) supporting substrate by the horizontal submersion deposition proc-ess without addition of any binder and conductive materials. The electrochemical properties of $\mathrm{MnO}_{2}$ thin-film EC prototypes in mild $\mathrm{Na}_{2} \mathrm{SO}_{4}$ aqueous electrolyte were evaluated using various established electrochemical characterization techniques. The effect of voltammetric scan rates, prolonged cycling, electrolyte composition, and concentration on the capacitive behaviors of $\mathrm{MnO}_{2}$ thin-film EC prototypes were reported.

\section{Experimental}

A stable manganese dioxide $\left(\mathrm{MnO}_{2}\right)$ sol was prepared based on method reported by Perez-Benito et al. [11]. Typically, $5 \mathrm{~mL}$ of potassium permanganate $\left(1.0 \times 10^{-1} \mathrm{M}\right)$ and $10 \mathrm{~mL}$ of sodium thiosulfate $\left(1.88 \times 10^{-2} \mathrm{M}\right)$ were mixed in ultrapure water $(18.2 \mathrm{M} \Omega . \mathrm{cm})$ to form $50 \mathrm{~mL}$ of homogenous dark brown $\mathrm{MnO}_{2}$ sol. $\mathrm{MnO}_{2}$ thin films of uniform thickness were deposited directly onto nickel-coated PET substrate using the horizontal submersion deposition process developed by our research group [12]. In this deposition process, a horizontally mounted nickel-coated PET substrate was being submerged completely in a measured volume of $\mathrm{MnO}_{2}$ sol for a predetermined duration. The excess sol was then siphoned off and the deposited film on the substrate was air-dried at ambience temperature. This deposition process was repeated for the desired number of times in order to obtain different film thicknesses. Deposited $\mathrm{MnO}_{2}$ thin films were heat treated at $200^{\circ} \mathrm{C}$ in air for one hour and then used to fabricate $\mathrm{MnO}_{2}$ thin-film EC prototypes of dualplanar configuration comprising interdigitated array (IDA) electrodes.

Well-dispersed $\mathrm{MnO}_{2}$ nanoparticles and deposited $\mathrm{MnO}_{2}$ thin films were characterized by a scanning electron microscope (SEM; JEOL JSM 6390LA) and a transmission electron microscope (TEM; JEOL JEM-1230). $\mathrm{MnO}_{2}$ EC prototypes in $0.2 \mathrm{M} \mathrm{Na}_{2} \mathrm{SO}_{4}$ aqueous electrolyte were characterized by cyclic voltammetry (CV), electrochemical impedance spectroscopy (EIS), and galvanostatic charge/discharge (GCD) which were operated on a computer interfaced and softwaredriven potentiostat/galvanostat (PARSTAT 2263). Effects of experimental parameters such as $\mathrm{CV}$ scan rates, electrolyte composition, and concentration on the capacitive behaviors of $\mathrm{MnO}_{2}$ EC prototypes were investigated. The specific capacitances of $\mathrm{MnO}_{2}$ EC prototypes were determined from both cyclic voltammograms, Nyquist plots, and constant current discharge curves based on the following equations, respectively

$$
C_{\mathrm{sp}}=\frac{1}{m \Delta V} \int I \delta t
$$

where $m$ is the mass of electroactive materials, $\Delta V$ is the scan potential window, and $I \delta t$ represents the instantaneous anodic charge at any given time

$$
C_{\mathrm{sp}}=-\frac{1}{m \cdot \omega Z_{\mathrm{img}}},
$$

where $\omega(=2 \pi f)$ is the angular frequency, $Z_{\text {img }}$ is the imaginary impedance, and impedances at both frequencies of $100 \mathrm{mHz}$ and $10 \mathrm{mHz}$ were used

$$
C_{\mathrm{sp}}=\frac{I \cdot t}{m \cdot \Delta V},
$$

where $I$ is the discharge current density, $t$ is the discharge time, and $\Delta V$ is the potential difference before and after discharge. The total electroactive mass loading, $m$, of the EC prototype was determined by atomic absorption spectroscopy (AAS) based on the stoichiometric formula weight of $\mathrm{MnO}_{2}$, at $86.94 \mathrm{~g} / \mathrm{mol}$.

\section{Results and Discussion}

3.1. Microstructural Characterization of $\mathrm{MnO}_{2}$ Thin Films. $\mathrm{MnO}_{2}$ sol synthesized in this study consisted of uniformsized $\mathrm{MnO}_{2}$ nanoparticles (20-40 nm in diameter) with aggregated nanofibrillar structures radiating outwards from the centre of each nanoparticle (Figure 1(a) and inset). $\mathrm{MnO}_{2}$ nanoparticles were observed to aggregate into clusters initially, which subsequently reorganized into longitudinal bundles of particle clusters (Figures 1(b) and 1(c)). Alignment and association of these longitudinal bundles of loosely packed $\mathrm{MnO}_{2}$ nanoparticles led to the formation of $\mathrm{MnO}_{2}$ thin films with highly porous microstructure.

Pronounced changes were observed in the surface morphology of $\mathrm{MnO}_{2}$ thin-film electrodes after prolonged voltammetric cycling. Figures $2(\mathrm{a})-2(\mathrm{~d})$ shows SEM micrographs of the cross-sectional edge of $\mathrm{MnO}_{2}$ thin-film electrode before and after voltammetric cycling. The heattreated $\mathrm{MnO}_{2}$ thin-film electrode was observed initially to consist of densely packed block-like microstructure (Figure 2(a)). However, this densely packed microstructure was replaced by microsized spherical particles after 50 charge/discharge cycles. A magnified SEM micrograph of such a dispersed microsized spherical particles revealed very irregular and rough surface morphology (Figure 2(b), inset), which subsequently evolved into irregular petal-like structure (Figure 2(c), inset) upon cycling for 100 cycles. Upon further prolonged cycling, an interconnected petallike macroporous morphology was observed (Figure 2(d)). Lin and Chen had reported $\mathrm{MnO}_{2}$-coated graphite electrodes of similar surface morphology, which was attributed to the dissolution and redeposition of amorphous $\mathrm{MnOOH}$, an electrochemically active product of $\mathrm{MnO}_{2}$ [13]. The porous microstructure is electrochemically favorable since it could provide substantially larger spatial clearance for electrode expansion and contraction during cycling, thereby preventing any physical degradation of electrode due to high internal stress [14]. Wei et al. had proposed a more comprehensive mechanism involving the dissolution and 


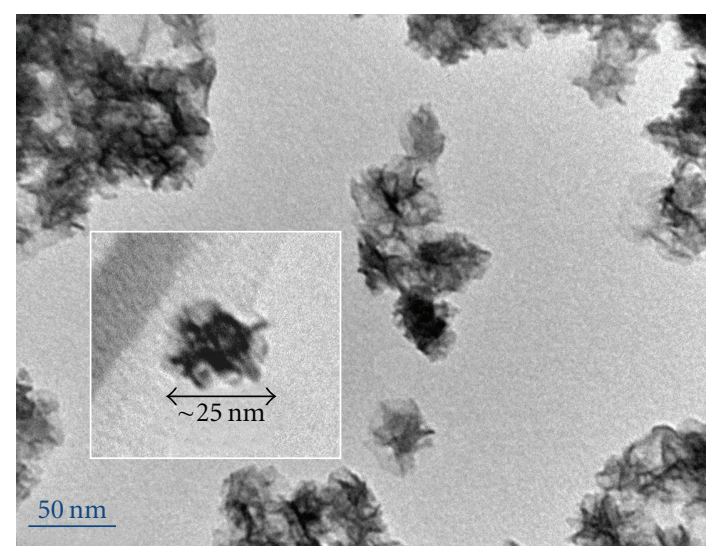

(a)

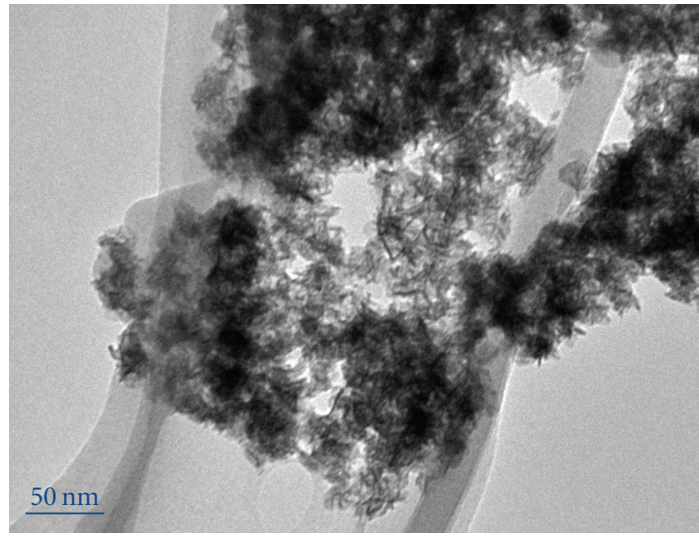

(b)

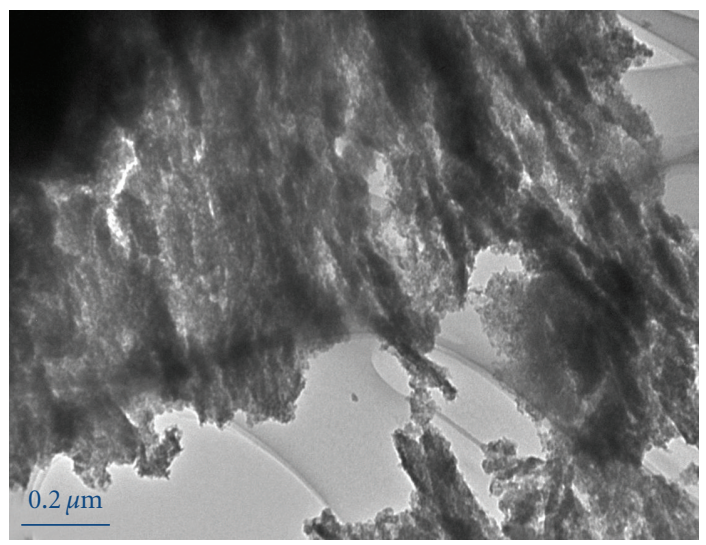

(c)

FIGURE 1: TEM micrographs of (a) dispersed $\mathrm{MnO}_{2}$ nanoparticles (scale bar is $50 \mathrm{~nm}$; inset shows an individual $\mathrm{MnO}_{2}$ nanoparticle with nanofibrillar structure), (b) aggregated $\mathrm{MnO}_{2}$ nanoclusters (scale bar is $50 \mathrm{~nm}$ ), and (c) longitudinal bundles of $\mathrm{MnO}_{2}$ nanoclusters (scale bar is $0.2 \mu \mathrm{m}$ )

redeposition of manganese ions which led to the formation of petal-shaped nanosheet microstructure of $\mathrm{MnO}_{2}$ electrode upon prolonged cycling [15]. The morphological characteristics of the electroactive material could significantly affect the faradaic reactions associated with charge-transfer and/or cations/protons intercalation into the bulk phase of electroactive material.

During electrochemical characterization, the cathodic current generated for the scan cycle from $+0.9 \mathrm{~V}$ to $0.0 \mathrm{~V}$ was attributed to the reduction of $\mathrm{Mn}^{4+}$ to $\mathrm{Mn}^{2+}$ whereas $\mathrm{Mn}^{2+}$ ions would be oxidized to $\mathrm{MnO}_{2}$ during the reverse scan cycle, and subsequently deposited as the petal-shaped surface morphology of the electrode. Since these pseudocapacitive reactions occurred almost exclusively at the outermost layer of the $\mathrm{MnO}_{2}$ electrode, petal-shaped microstructures was formed initially on the surface of electrode, but gradually extended into the bulk phase of electroactive material upon prolonged voltammetric cycling. Instead of being confined to the first few nanometers of electrode surface, electroactive material of higher porosity should lead to enhanced utilization by facilitating faradaic reactions through intercalation of protons/electrolyte cations into the bulk phase of the $\mathrm{MnO}_{2}$ electrode [16]. The penetration depth of electrolyte cations depends greatly on the porosity of the electrode matrix [17]. Besides, such surface morphological transformation could lead to improved capacitive behaviors of $\mathrm{MnO}_{2}$ electrode due to reduction in the interparticle contact resistance and hence higher electrical conductivity.

Figure $3(\mathrm{a})$ shows the cyclic voltammograms $(\mathrm{CVs})$ of $\mathrm{MnO}_{2}$ thin-film EC prototype in $0.2 \mathrm{M} \mathrm{Na}_{2} \mathrm{SO}_{4}$ aqueous electrolyte. $\mathrm{MnO}_{2}$ thin-film EC prototypes exhibited good capacitive behaviors within the potential window of $-0.9 \mathrm{~V}$ to $+0.9 \mathrm{~V}$ at a scan rate of $50 \mathrm{mV} / \mathrm{s}$, as evidenced by the near rectangular shape of $\mathrm{CV}$ curves. The specific capacitance of $\mathrm{MnO}_{2}$ EC prototype, as determined by integrating the area of CV curve, was substantially larger than values reported for carbon-based systems of similar weight or volume [18]. For carbon-based systems, charges are normally stored electrostatically at the electrolyte/electrode interfacial region, and is therefore dependent upon the total specific surface area of electroactive material being exposed to the electrolyte. In contrast, the capacitance of $\mathrm{MnO}_{2}$-based EC prototype arises from rapid and reversible faradaic reactions between electrolyte ions and the electroactive material. No redox peaks were discernible from these rectangular CV curves even after prolonged charge/discharge cycling for up to 300 


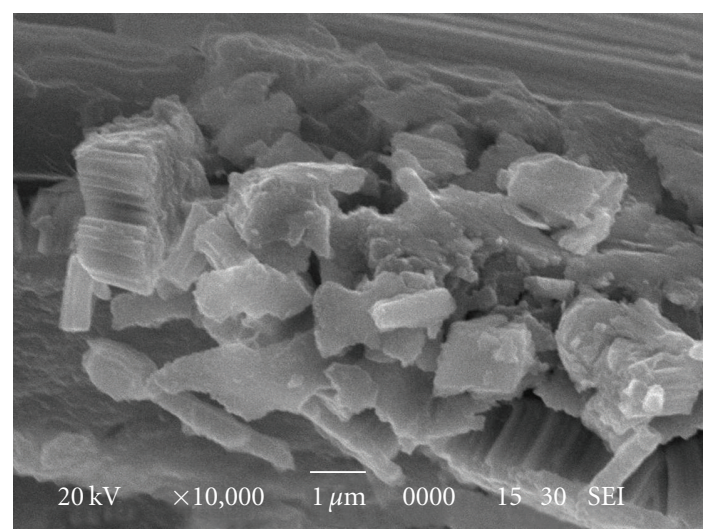

(a)

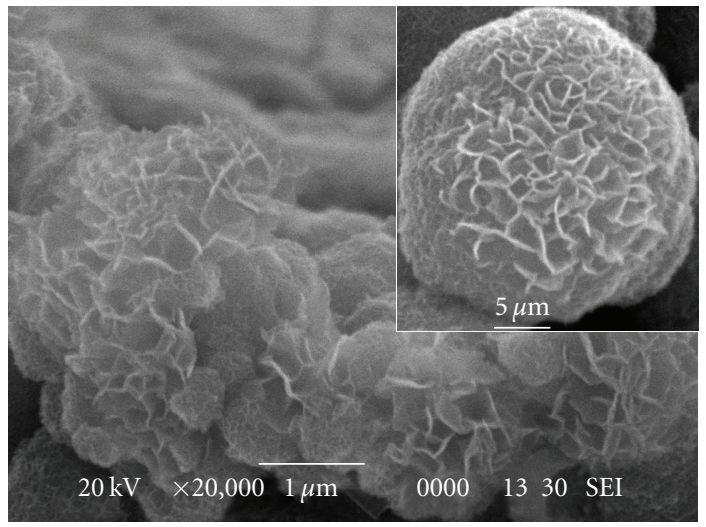

(c)

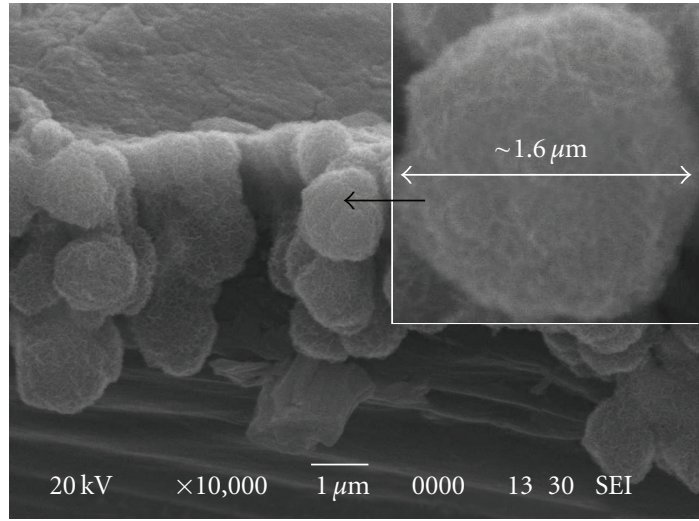

(b)

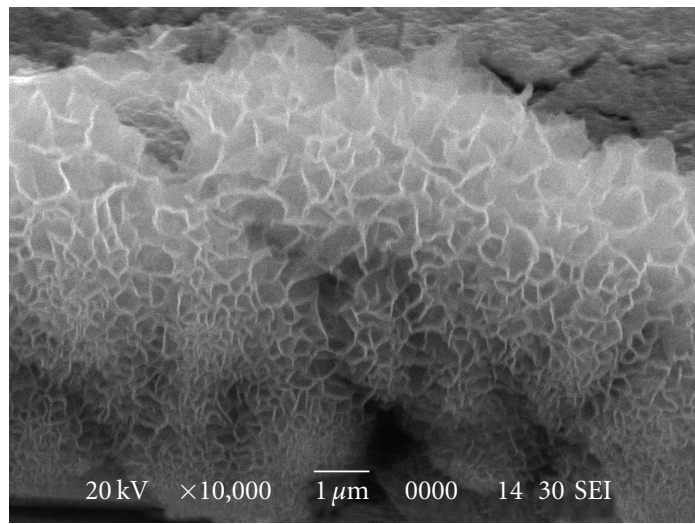

(d)

FIGURE 2: SEM micrographs of $\mathrm{MnO}_{2}$ thin film after cyclic voltammetric cycling in $0.2 \mathrm{M} \mathrm{Na}_{2} \mathrm{SO}_{4}$ liquid electrolyte for (a) 0 cycle, (b) 50 cycles (inset shows a spherical microparticle), (c) 100 cycles (inset shows enlarged microparticle with petal-like structure), and (d) 300 cycles.

cycles. This could be attributed to the excellent phase stability and reversibility of $\mathrm{MnO}_{2}$ thin films. According to Conway, the capacitance of metal-oxide electrodes is mainly attributed to pseudocapacitance, and supplemented by approximately $5 \%$ or less of electrostatic double-layer capacitance [18]. As such, the contribution of double-layer capacitance was deemed negligible, and was therefore excluded in calculating total specific capacitance of $\mathrm{MnO}_{2}$ EC prototypes.

3.2. Cyclic Voltammetry $(\mathrm{CV})$. The integrated areas within the CV curves were observed to increase substantially after the morphological transformation from the initial agglomerated plate-like to interconnected petal-like porous morphology. This morphological characteristic of $\mathrm{MnO}_{2}$ films resembled the "sand-rose-" like structure of $\mathrm{MnO}_{2}$ films synthesized by Beaudrouet et al. via the reduction of $\mathrm{KMnO}_{4}$ or $\mathrm{NaMnO}_{4}$ in acidic medium [19]. The intercalation of cations into the bulk electroactive material was facilitated by $\mathrm{MnO}_{2}$ film of high specific surface area. The specific capacitance of $\mathrm{MnO}_{2}$ thin-film EC prototypes was observed to increase substantially from $124 \mathrm{~F} / \mathrm{g}$ to $230 \mathrm{~F} / \mathrm{g}$ after 300 charge/discharge cycles (Figure 3(b)). The enhanced electrochemical performance associated with morphological changes could be attributed to increased surface-to-volume ratio of the $\mathrm{MnO}_{2}$ thin film as shown in Figures 2(a)2(d) and discussed in the preceding section. $\mathrm{MnO}_{2}$ thin films of highly porosity and specific surface area would enable easy accessibility of cations and/or protons during charge/discharge cycles. The diffusion pathway could be significantly shortened for films of macroporous structure as compared to that of densely packed block-like structure [20]. The lower specific capacitance observed during initial cycles prior to any morphological transformation could be attributed to limited cationic diffusion and/or low electrolyte penetration into the bulk of electrode material.

3.3. Electrochemical Impedance Spectroscopy (EIS). Figure 4 shows the Nyquist plots of $\mathrm{MnO}_{2}$ EC prototype after different charge/discharge cycles and the proposed equivalent circuit model. The capacitive behavior of $\mathrm{MnO}_{2}$ EC prototype was represented by the almost vertical line at the low frequency region. Pronounced shift of impedance plots upon cycling was observed in the low frequency region indicating substantial reduction in the total impedance (summation of real and imaginary impedances) of EC prototypes. The total impedance or equivalent series resistance (ESR) of the EC prototype could be separated into constituent impedances such as electrolyte resistance, contact resistance between 


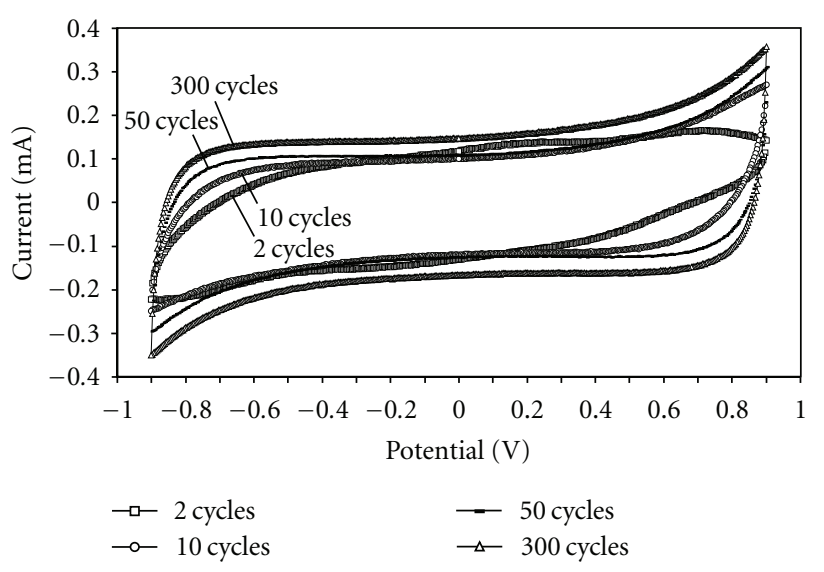

(a)

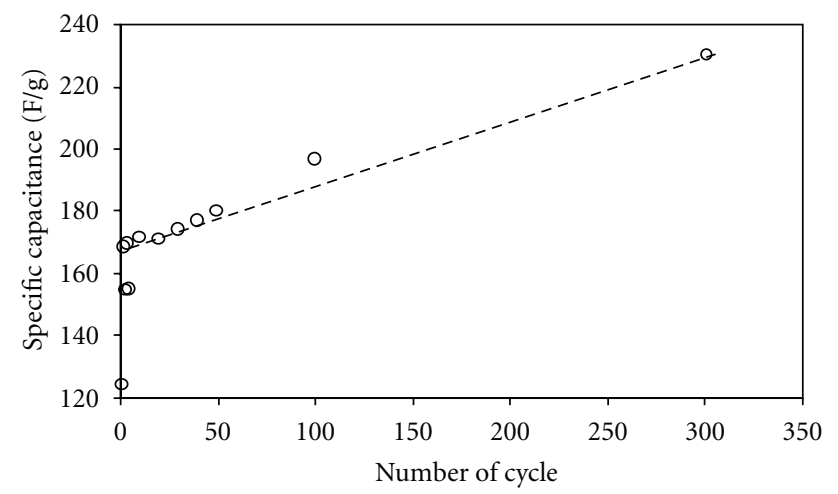

(b)

Figure 3: (a) Cyclic voltammograms of $\mathrm{MnO}_{2}$ thin-film EC prototypes evaluated in $0.2 \mathrm{M} \mathrm{Na}_{2} \mathrm{SO}_{4}$ aqueous electrolyte cycled for up to 300 cycles, and (b) specific capacitance of $\mathrm{MnO}_{2}$ thin-film EC prototypes $(\mathrm{F} / \mathrm{g})$ as a function of cycle number.

the nickel current collector and $\mathrm{MnO}_{2}$ electrode, contact resistance between $\mathrm{MnO}_{2}$ nanoparticles, and the intrinsic resistance of $\mathrm{MnO}_{2}$ electroactive material.

Figure 5 shows the impedance data of the $\mathrm{MnO}_{2}$ EC prototype which was being fitted to the equivalent circuit model $R_{\Omega}\left(Q\left(R_{\mathrm{ct}} R_{w}\right)\right)\left(Q_{l} R_{l}\right)$. This model comprises basic electronic components such as $R_{\Omega}$, uncompensated electrolyte resistance, $R_{\mathrm{ct}}$, charge-transfer resistance, $R_{W}$, Warburg resistance, and CPE, constant phase element. Two additional electronic components, $\mathrm{CPE}_{l}$ and $R_{l}$ were added for taking into account the formation of an ionically conductive passivative layer on the $\mathrm{MnO}_{2}$ electrode, as was commonly observed in battery electrodes [21].

The $R_{\mathrm{ct}}$ values obtained by simulating the experimental results using the equivalent circuit model were observed to be rather consistent throughout the charge/discharge cycles (Figure 6(a)). This is expected because charge transfer is not affected by the electrode morphology but is affected by the oxidation states of manganese and active hopping sites within the electrode $[2,22]$. Likewise, the $R_{w}$ value which represented proton/cation diffusion was also quite consistent and varied slightly between $0.12 \mathrm{~m} \Omega$ and $0.14 \mathrm{~m} \Omega$ (Figure 6(a)). The consistent ratio of $R_{\mathrm{ct}}$ to $R_{w}$ indicated

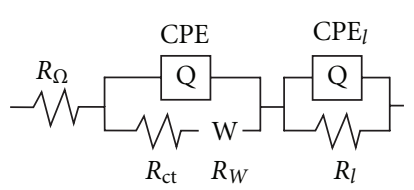

(a)

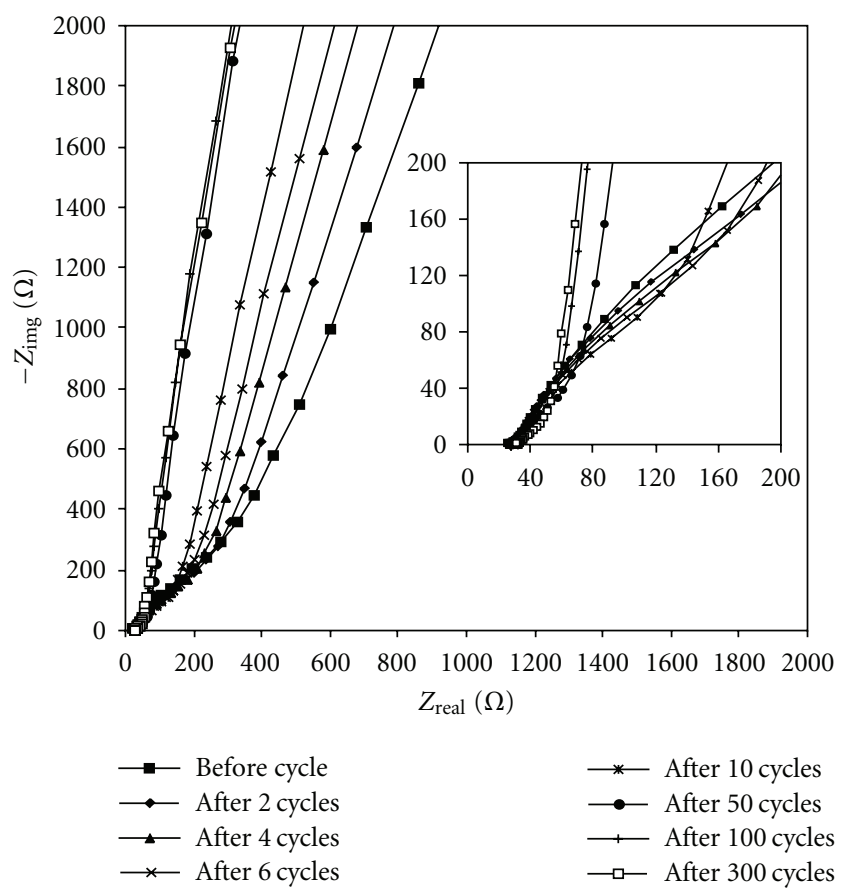

(b)

Figure 4: (a) Equivalent circuit model of $\mathrm{MnO}_{2}$ thin-film EC prototypes, (b) impedance plots of electrochemical capacitors (EC) at different charge/discharge cycle (inset shows the high-frequency regions of impedance plots).

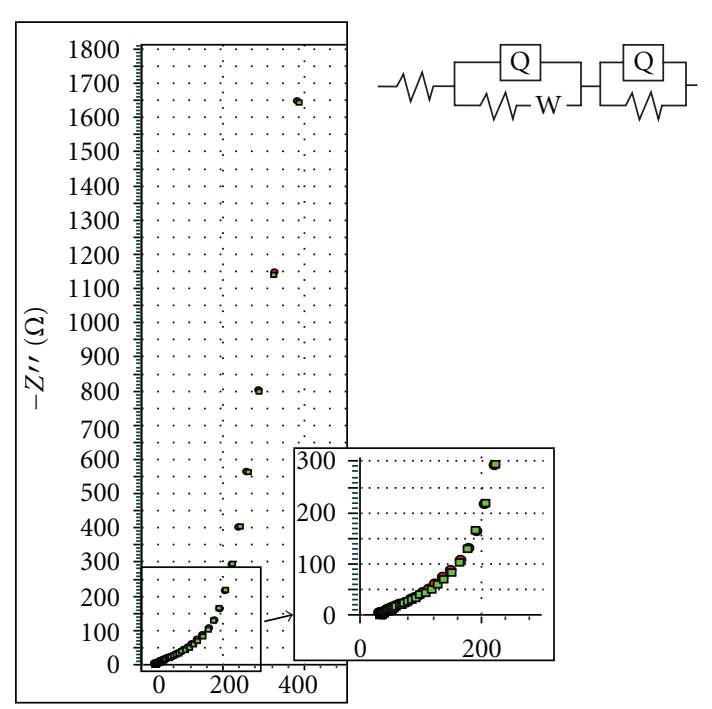

FIGURE 5: Comparison of experimental impedance data (o) with fitted impedance data $(\square)$ based on the equivalent circuit model $R_{\Omega}\left(Q\left(R_{\mathrm{ct}} R_{w}\right)\right)\left(Q_{l} R_{l}\right)$; chi-square value $=3.61 \times 10^{-4}$. Insets show the equivalent circuit model and the high-frequency region of the Nyquist plot. 


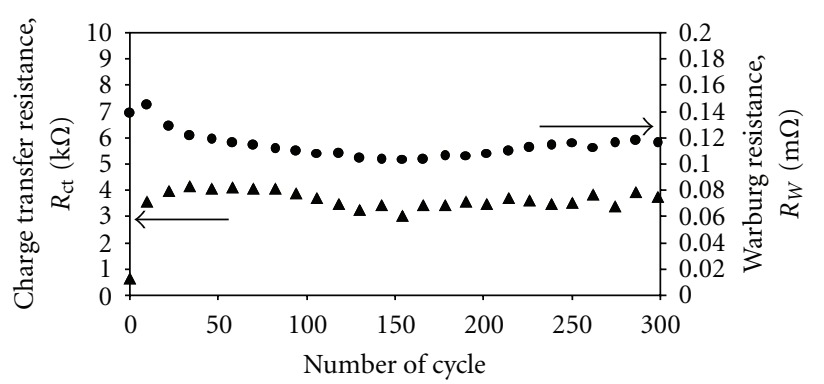

(a)

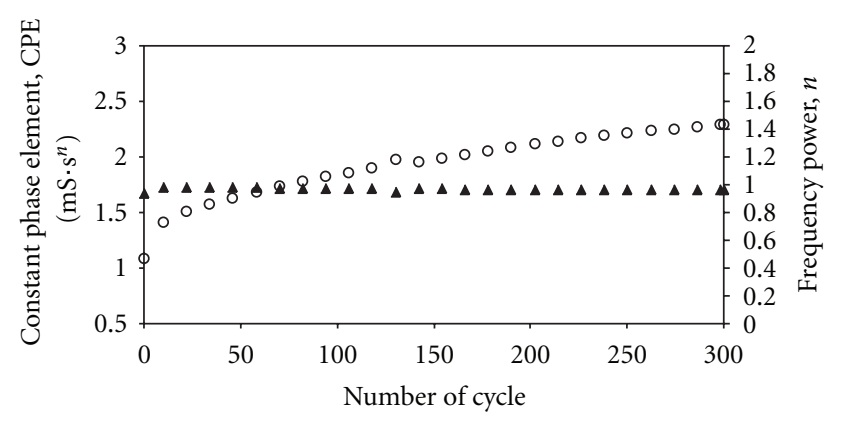

○ Constant phase element, CPE

^ Frequency power, $n$

(b)

Figure 6: (a) Charge-transfer and Warburg resistances, and (b) constant phase element (CPE) and frequency power $(n)$, at different charge/discharge cycle.

excellent electrochemical stability of $\mathrm{MnO}_{2}$ thin films. The reversibility of redox reaction had been reported to increase with the amount of hydrates presence within the electroactive material by providing electrochemically facile sites for charge-transfer reaction and cation diffusion [22]. A similar equivalent circuit model has been reported by Xu et al. [23] to study the charge storage mechanism of manganese dioxide electrode in various neutral electrolytes [23].

Under the finite diffusion condition, the capacitive behavior was attributed to the accumulation of cations at the impermeable interface of the electrode [24]. Since the wide range of dispersion in pore sizes of electrode gave rise to nonideal capacitive behavior, the capacitance in the equivalent circuit model was represented by the frequencydependent constant phase element (CPE). In the lowfrequency region ( $10 \mathrm{mHz}$ or below), the impedance phase shifted along the real impedance axis to almost $\pi / 2$ which was indicative of excellent capacitive behavior (Figure 4) [24]. The frequency power, $n$, representing phase angle $n * \pi / 2$ was observed to be closed to one throughout the cycling, and thus further substantiated the outstanding capacitive behavior of the $\mathrm{MnO}_{2}$ EC prototypes. As shown in Figure 6(b), the constant phase element was directly affected by the porosity or specific surface area of the electroactive materials and was observed to increase gradually with increasing number of charge/discharge cycles. The improved capacitive behaviors of the $\mathrm{MnO}_{2}$ EC prototypes upon prolonged cycling could
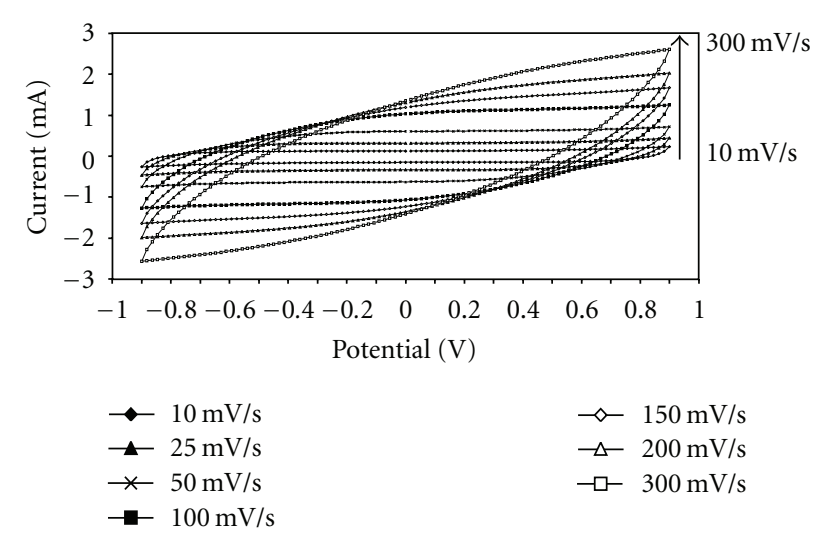

FIGURE 7: Effect of scan rates on the shape of cyclic voltammograms. Only the 50th cycle of each cyclic voltammogram is shown.

be attributed to the morphological transformation of $\mathrm{MnO}_{2}$ thin-film electrodes as discussed in the preceding sections.

3.4. Effect of Scan Rate. The effect of scan rates was investigated in order to elucidate the underlying charge-storage mechanisms of $\mathrm{MnO}_{2}$ thin-film EC prototypes. The rate of cation diffusion into the bulk electroactive material could be controlled by applying different scan rates during the $\mathrm{CV}$ test. Figure 7 shows $\mathrm{CV}$ curves of $\mathrm{MnO}_{2}$ thin-film EC prototypes at various scan rates between $10 \mathrm{mV} / \mathrm{s}$ and $300 \mathrm{mV} / \mathrm{s}$. Our findings concurred with results reported by Roberts and Slade [25]. Based on the proposed charge-storage mechanisms of $\mathrm{MnO}_{2}$ EC prototypes, the rate of intercalation/ deintercalation of protons and/or cations into/out of the bulk $\mathrm{MnO}_{2}$ thin films would be affected by the scan rate $[2,26]$. As the scan rate was increased, a clear deviation from the rectangular CV curve was observed. At low scan rate, the diffusion controlled intercalation/deintercalation of cations could access almost all available pores, resulting in an almost rectangular CV curve which was indicative of an ideal capacitive behavior. As the scan rate was increased, a deviation from the rectangular shape of $\mathrm{CV}$ curve was observed (Figure 7). At high scan rate, the diffusion of cations into the $\mathrm{MnO}_{2}$ matrix was reduced due to diminished interactions of cations with the $\mathrm{MnO}_{2}$ electrode surface.

Nevertheless, a significant portion of the bulk electroactive material was shown to be inaccessible by cations even at a very low scan rate as the pore size of $\mathrm{MnO}_{2}$ thin film could be too small for cations to penetrate, especially for cations with some degree of solvation [15]. According to Toupin et al. the faradaic reactions were confined to the surface of $\mathrm{MnO}_{2}$ films due to the limited rate of proton/cations diffusion into the bulk of the film. The high internal resistance of the $\mathrm{MnO}_{2}$ thin-film electrode could have also contributed towards the limiting rate of proton/cations diffusion into the $\mathrm{MnO}_{2}$ lattice $[27,28]$. This could plausibly explain the low specific capacitance values of $\mathrm{MnO}_{2}$ thin films as compared to its theoretical value. 


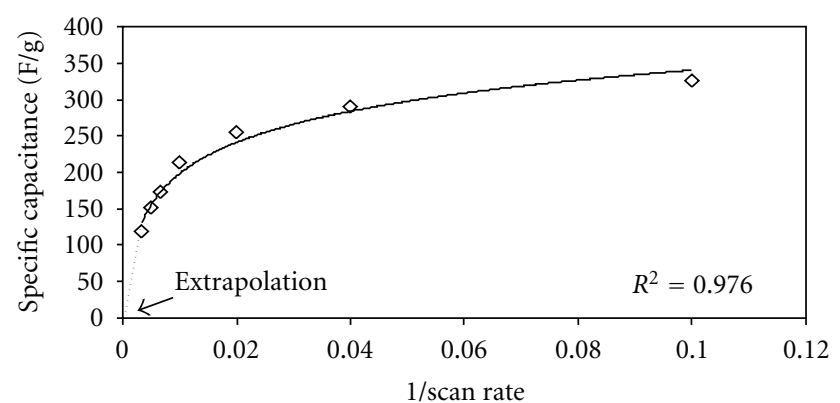

Figure 8: The specific capacitance (F/g) of the $\mathrm{MnO}_{2}$ thin-film EC prototypes versus the inverse of scan rate ( $1 /$ scan rate).

TABle 1: Specific capacitance (F/g) of $\mathrm{MnO}_{2}$ thin-film electrochemical capacitor prototypes calculated from cyclic voltammograms (CVs) at different scan rates, and electrochemical impedance spectroscopy (EIS) at the frequency of $10 \mathrm{mHz}$.

\begin{tabular}{lccc}
\hline $\begin{array}{l}\text { Scan rate } \\
(\mathrm{mV} / \mathrm{s})^{\mathrm{a}}\end{array}$ & \multicolumn{3}{c}{$\begin{array}{c}\text { Specific capacitance (F/g) } \\
\text { EIS }^{\mathrm{b}}\end{array}$} \\
\hline 10 & 327 & 289 & $\mathrm{GCD}^{\mathrm{c}}$ \\
25 & 291 & 290 & 239 (discharge) \\
50 & 256 & 290 & \\
100 & 214 & 288 & \\
150 & 174 & 270 & \\
200 & 152 & 261 & \\
300 & 119 & 266 & \\
\hline
\end{tabular}

${ }^{a}$ The scan rate was applicable for CV only.

${ }^{b}$ EIS was conducted on the same electrode immediately after each CV test.

${ }^{\mathrm{c}}$ Galvanostatic charge/discharge conducted at a current density of $0.08 \mathrm{~mA}$.

The rate of diffusion of protons/cations into the bulk of $\mathrm{MnO}_{2}$ nanoparticulate matrix was observed to be inversely related to the scan rate, with diminution of specific capacitance as the scan rate was increased (Figure 8). Hence, plots of specific capacitance versus inverse of scan rate should provide a good representation of the electrochemical characteristics of $\mathrm{MnO}_{2}$-based EC prototypes. The observed inverse correlation could be attributed to the activation and concentration polarization at high scan rates [29]. The higher the scan rate, the lower the diffusivity of protons/cations into the bulk of electroactive material. Henceforth, only the outer surface of $\mathrm{MnO}_{2}$ thin films would be utilized to generate pseudocapacitance [30].

Table 1 shows the substantial decrease in specific capacitance values from $327 \mathrm{~F} / \mathrm{g}$ to $119 \mathrm{~F} / \mathrm{g}$ as determined by CV at scan rates of $10 \mathrm{mV} / \mathrm{s}$ and $300 \mathrm{mV} / \mathrm{s}$, respectively. However, further decrease in the scan rate would lead to insignificant increase in the specific capacitance when the threshold level had been reached. Besides, the inherent thickness and microstructure of $\mathrm{MnO}_{2}$ films could have impeded further penetration of protons or cations. The voltammetric charge on the outer surface of the electroactive material could be inferred by extrapolation of an expected linear correlation between the specific capacitance and the inverse of scan rate [30]. Nevertheless, such a linear correlation

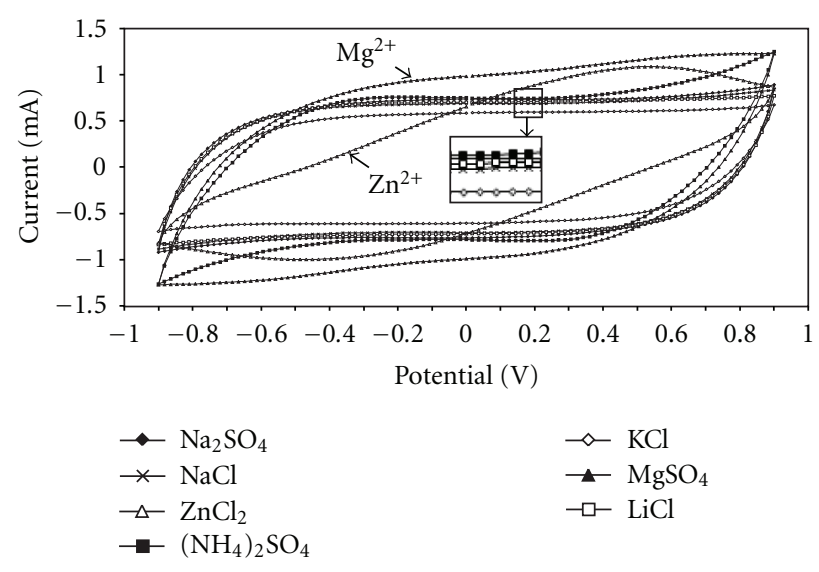

FIGURE 9: Effect of electrolyte composition on the shape of cyclic voltammograms at a scan rate of $50 \mathrm{mV} / \mathrm{s}$. Inset shows a magnified portion of various CV curves.

was not obtained in the present study, and the extrapolated specific capacitance value at infinite scan rate was very small. This observation was in consonance with the proposed pseudocapacitive charge-storage mechanism due to faradaic reactions which were sensitive to diffusion phenomena of electroactive species into the bulk porous electrode materials $[19,31]$.

All $\mathrm{MnO}_{2}$ EC prototypes were further evaluated with electrochemical impedance spectroscopy (EIS) immediately after every $\mathrm{CV}$ test at various scan rates, as well as the galvanostatic charge/discharge (GCD) technique. Specific capacitance values of $\mathrm{MnO}_{2}$ thin-film electrochemical capacitor prototypes as determined by various techniques are as shown in Table 1, and they are comparable under specific experimental conditions. Changes in specific capacitance values of EC prototypes as determined by EIS were negligible. On the contrary, specific capacitance values of EC prototypes as determined by $\mathrm{CV}$ were observed to decrease by about $63 \%$ when the scan rate was increased from $10 \mathrm{mV} / \mathrm{s}$ to $300 \mathrm{mV} / \mathrm{s}$. These results further substantiated our earlier findings that a higher scan rate would significantly attenuate the capacitive performance of the EC prototypes. Our findings concurred with results reported by several previous studies, all of which had indicated logarithmic reduction of specific capacitance values with increment of scan rate $[19,29,32,33]$.

3.5. Effect of Electrolytes. Figure 9 shows the cyclic voltammograms of EC prototypes evaluated in different aqueous electrolytes at a scan rate of $50 \mathrm{mV} / \mathrm{s}$. Near-rectangular shape of $\mathrm{CV}$ curves were observed for all electrolytes except for $\mathrm{ZnCl}_{2}$ electrolyte indicating the excellent capacitive behavior and high cycling reversibility of $\mathrm{MnO}_{2}$ EC prototypes. $\mathrm{MnO}_{2}$ EC prototypes were observed to exhibit a higher specific capacitance value of $354 \mathrm{~F} / \mathrm{g}$ in $\left(\mathrm{NH}_{4}\right)_{2} \mathrm{SO}_{4}$ aqueous electrolyte as compared with prototypes in aqueous electrolytes containing alkaline cations such as $\mathrm{Li}^{+}, \mathrm{Na}^{+}$, and $\mathrm{K}^{+}$ions $(253-325 \mathrm{~F} / \mathrm{g})$. This could be attributed to aqueous electrolyte containing nonmetallic cations such as 
TABle 2: Specific capacitance (F/g) of $\mathrm{MnO}_{2}$-based electrochemical capacitors in different aqueous electrolytes calculated from cyclic voltammograms (CVs) at scan rate of $50 \mathrm{mV} / \mathrm{s}$ and electrochemical impedance spectroscopy (EIS) at the frequency of $10 \mathrm{mHz}$.

\begin{tabular}{|c|c|c|c|c|c|}
\hline Cations [0.2 M] & $\begin{array}{c}\text { Mobility } \\
\left(10^{-8} \mathrm{~m}^{2} \mathrm{~s}^{-1} \mathrm{~V}\right)[29]\end{array}$ & $\begin{array}{c}\text { Conductivity } \\
\left(10^{-4} \mathrm{~m}^{2} \mathrm{~S} \mathrm{~mol}^{-1}\right) \\
{[29]}\end{array}$ & $\begin{array}{l}\text { Radius of hydrated } \\
\text { cations }(\sim \AA)[25]\end{array}$ & $\begin{array}{l}\text { Specific capacitance } \\
\text { from } C V(\mathrm{~F} / \mathrm{g})\end{array}$ & $\begin{array}{l}\text { Specific capacitance } \\
\text { from EIS }(\mathrm{F} / \mathrm{g})\end{array}$ \\
\hline $\mathrm{NH}_{4}^{+}$ & NA & NA & 3.32 & 354 & 330 \\
\hline $\mathrm{K}^{+}$ & 7.6 & 73.5 & 3.32 & 308 & 306 \\
\hline $\mathrm{Na}^{+}\left(\right.$in $\left.\mathrm{Na}_{2} \mathrm{SO}_{4}\right)$ & 5.2 & 50.1 & 3.59 & 325 & 303 \\
\hline $\mathrm{Na}^{+}($in $\mathrm{NaCl})$ & 5.2 & 50.1 & 3.59 & 309 & 316 \\
\hline $\mathrm{Li}^{+}$ & 4.0 & 38.7 & 3.84 & 253 & 274 \\
\hline $\mathrm{Mg}^{2+}$ & NA & NA & 4.28 & 436 & 390 \\
\hline $\mathrm{Zn}^{2+}$ & NA & NA & 4.32 & 305 & NA \\
\hline
\end{tabular}

$\mathrm{NH}_{4}{ }^{+}$ions which possessed higher proton diffusion and ionic conductivity [29]. However, $\mathrm{MnO}_{2}$ EC prototypes in aqueous electrolyte containing $\mathrm{NH}_{4}{ }^{+}$ions showed lower cycling reversibility during electrochemical charge/discharge as evidenced by their CV curves of distorted rectangular shape [29]. Aqueous electrolyte containing $\mathrm{Zn}^{2+}$ ions appeared to be unsuitable for $\mathrm{MnO}_{2} \mathrm{EC}$ prototypes as exemplified by the distorted CV curve of distinctive redox peaks at both anodic and cathodic scans.

Table 2 shows specific capacitances values of $\mathrm{MnO}_{2} \mathrm{EC}$ prototypes as determined from both $\mathrm{CV}$ curves and EIS plots, which were found to be in agreement with each other. No pronounced correlation between specific capacitance of $\mathrm{MnO}_{2}$ EC prototype and different electrolyte cations was observed despite substantial differences in their hydration sphere radii. Results from both CV and EIS tests showed that $\mathrm{MnO}_{2}$ EC prototypes in aqueous electrolyte containing $\mathrm{Mg}^{2+}$ ions exhibited the highest specific capacitance value. Since $\mathrm{Mg}^{2+}$ ions did not undergo intense solvation which would have led to larger Stokes radius, and consequently lower ionic mobility in the porous region of electrode material [34]. Neither the large ionic radius of hydrated $\mathrm{Mg}^{2+}$ ions nor its higher oxidation state as compared to other hydrated cations constituted the limiting factors for the charge/discharge rate [35]. Although the highest specific capacitance value of EC prototypes was obtained in aqueous electrolyte containing $\mathrm{Mg}^{2+}$ ions, a slightly distorted CV curve was observed due to redox reactions that occurred during both anodic and cathodic scans.

The presence of appropriate cationic species in the electrolyte is essential for optimizing the pseudocapacitive performances of EC prototypes based on intercalation/ deintercalation processes that occur at the electrolyte/ electrode interfacial region. Selection of cationic species in the electrolyte should take into account the size of cations and their hydration spheres, as well as the chemical compatibility between electrode material and electrolyte. For instance, the high mobility of protons $\left(\mathrm{H}^{+}\right)(36.24$ $\times 10^{-8} \mathrm{~m}^{2} \mathrm{~s} / \mathrm{V}$ in $\left.\mathrm{H}_{2} \mathrm{O}\right)$ and their small ionic radii $(9 \AA)$ would enable rapid charging/discharging rate and higher specific capacitance. Unfortunately, few electrode materials (especially $\mathrm{MnO}_{2}$ ) are electrochemically inert in strong acidic electrolyte. Long-term cycling stability $(>10,000$

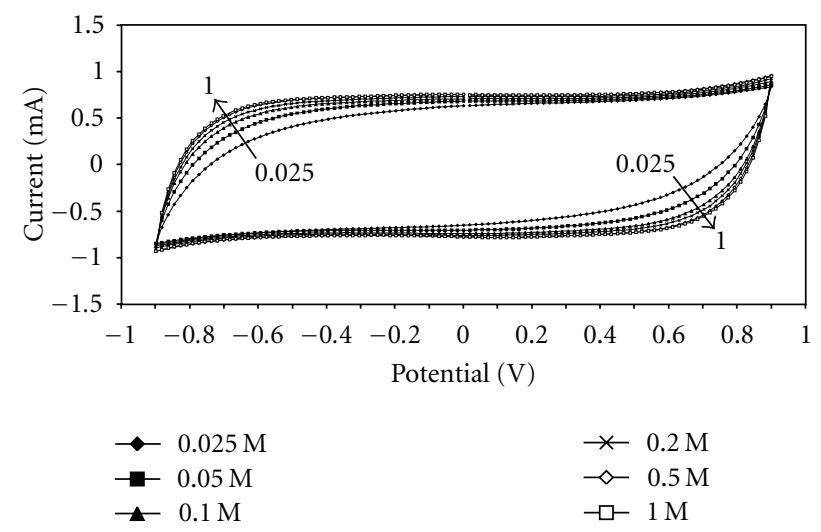

(a)

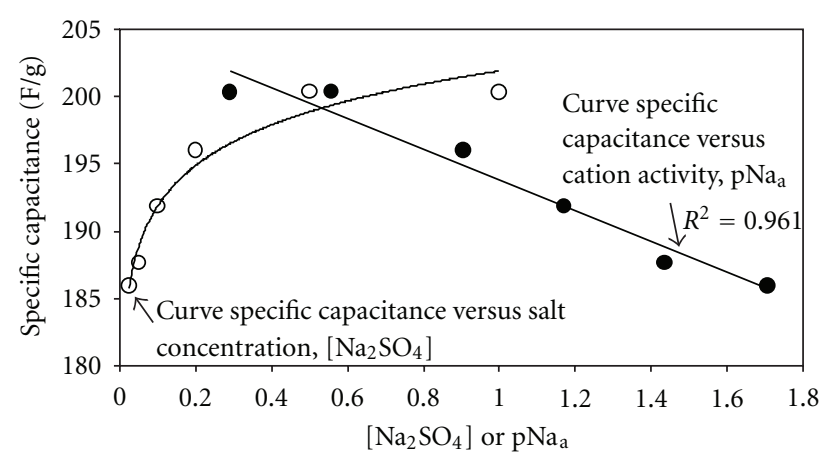

(b)

Figure 10: (a) Cyclic voltammograms in different $\mathrm{Na}_{2} \mathrm{SO}_{4}$ electrolyte concentration at a scan rate of $50 \mathrm{mV} / \mathrm{s}$, (b) specific capacitance $(\mathrm{F} / \mathrm{g})$ of the $\mathrm{MnO}_{2} \mathrm{EC}$ prototypes at different electrolyte concentration, $\left[\mathrm{Na}_{2} \mathrm{SO}_{4}\right]$, and cation activity, $\mathrm{pNa}_{\mathrm{a}}$.

charge/discharge cycles) was reported for $\mathrm{MnO}_{2}$-based electrode in electrolytes containing sulphate-based salts only [36].

3.6. Effect of Electrolyte Concentration. The effect of $\mathrm{Na}_{2} \mathrm{SO}_{4}$ electrolyte concentration on the specific capacitance of $\mathrm{MnO}_{2}$ EC prototypes was studied. Figure 10(a) shows cyclic voltammograms of $\mathrm{MnO}_{2} \mathrm{EC}$ prototypes in different $\mathrm{Na}_{2} \mathrm{SO}_{4}$ 
electrolyte concentrations between 0.025 and $1.000 \mathrm{M}$ at a fixed scan rate of $50 \mathrm{mV} / \mathrm{s}$. Specific capacitance values of $\mathrm{MnO}_{2}$ EC prototypes were observed to increase nonlinearly with increase in $\mathrm{Na}_{2} \mathrm{SO}_{4}$ electrolyte concentration. The highest specific capacitance value of approximately $200 \mathrm{~F} / \mathrm{g}$ was obtained at electrolyte concentrations above $0.5 \mathrm{M}$. At high electrolyte concentration, the presence of excessive $\mathrm{Na}^{+}$ions could either saturate electroactive sites or hinder access into the bulk of $\mathrm{MnO}_{2}$ electroactive material [28]. Figure 10(b) shows the relationship between specific capacitance and the cation concentration or cation activity, $\mathrm{pNa}_{\mathrm{a}}$, which can be calculated by the following equation:

$$
\text { Cation activity, } \mathrm{Na}_{\mathrm{a}}=f_{i} c
$$

where $f_{i}$ is activity coefficient and $c$ is the cation concentration. The activity coefficient, $f_{i}$ can be calculated according to the Debye-Hückel equation:

$$
\text { Activity coefficient, }-\log f_{i}=\frac{A z_{i} \sqrt[2]{I}}{1+B a ̊ \sqrt{I}} \text {, }
$$

where $A$ and $B$ are coefficients, which, in this case, $A=$ 0.5115 and $B=0.3291, z_{i}$ is the ion charge, $I$ is the ionic strength, and a is the hydrated ion size of the cation. The cation activity was used instead of cation concentration in order to reflect the actual cation concentration involved in the electrochemical reactions. A linear plot of the specific capacitance of $\mathrm{MnO}_{2}$ versus the cation activity $\left(R^{2}=0.96\right)$ was obtained (Figure 10(b)), indicating that the charging process of $\mathrm{MnO}_{2}$ was a first-order reaction with respect to the cation activity with a slope of -11.46 . The linear relationship implied that the charge/discharge process was mainly controlled by the intercalation/deintercalation of cations within the $\mathrm{MnO}_{2}$ electrode $[23,37]$.

\section{Conclusions}

Both electrochemical impedance spectroscopy and cyclic voltammetry had provided complimentary information on the capacitive behaviors of the $\mathrm{MnO}_{2}$ thin-film EC prototypes in a mild aqueous electrolyte. The capacitive behaviors of $\mathrm{MnO}_{2}$ thin-film EC prototypes were mainly attributed to the intercalation/deintercalation of protons and/or electrolyte cations into the electroactive material. The improved capacitive performance of the EC prototypes upon prolong charge/discharge cycling was associated with the morphological changes of $\mathrm{MnO}_{2}$ thin-film electrodes. Though the capacitive behaviors of the $\mathrm{MnO}_{2}$ EC prototypes were affected by electrolyte cations of different solvated sphere sizes, no pronounced correlation between them was evidenced. The specific capacitance of $\mathrm{MnO}_{2}$ EC prototypes decreased with increased $\mathrm{CV}$ scan rates within the range of $10 \mathrm{mV} / \mathrm{s}$ to $300 \mathrm{mV} / \mathrm{s} . \mathrm{MnO}_{2}$ thin-film EC prototypes fabricated in this study exhibited the highest specific capacitance of $327 \mathrm{~F} / \mathrm{g}$ at a slow CV scan rate of $10 \mathrm{mV} / \mathrm{s}$.

\section{Acknowledgment}

This paper was partially funded by Universiti Malaysia Sarawak (UNIMAS) through the award of a special fundamental research Grant 01(K03)/557/2005(56).

\section{References}

[1] S. C. Pang and M. A. Anderson, "Novel electrode materials for electrochemical capacitors: part II. Material characterization of sol-gel-derived and electrodeposited manganese dioxide thin films," Journal of Materials Research, vol. 15, no. 10, pp. 2096-2106, 2000.

[2] S. C. Pang, M. A. Anderson, and T. W. Chapman, "Novel electrode materials for thin-film ultracapacitors: comparison of electrochemical properties of sol-gel-derived and electrodeposited manganese dioxide," Journal of the Electrochemical Society, vol. 147, no. 2, pp. 444-450, 2000.

[3] S. F. Chin, S. C. Pang, and M. A. Anderson, "Material and electrochemical characterization of tetrapropylammonium manganese oxide thin films as novel electrode materials for electrochemical capacitors," Journal of the Electrochemical Society, vol. 149, no. 4, pp. A379-A384, 2002.

[4] US Department of Energy, "Basic research needs for electrical energy storage," Report of the basic energy sciences workshop for electrical energy storage, July 2007, http:// science.energy.gov/bes/news-and-resources/reports/basic-research-needs/.

[5] S. F. Chin and S. C. Pang, "Tetrapropylammonium-manganese oxide/polypyrrole hybrid nanocomposite thin films as novel electrode materials for supercapacitors," Materials Chemistry and Physics, vol. 124, no. 1, pp. 29-32, 2010.

[6] J. K. Chang, M. T. Lee, and W. T. Tsai, "In situ Mn Kedge X-ray absorption spectroscopic studies of anodically deposited manganese oxide with relevance to supercapacitor applications," Journal of Power Sources, vol. 166, no. 2, pp. 590594, 2007.

[7] S. F. Chin, S. C. Pang, and M. A. Anderson, "Self-assembled manganese dioxide nanowires as electrode materials for electrochemical capacitors," Materials Letters, vol. 64, no. 24, pp. 2670-2672, 2010.

[8] P. Yu, X. Zhang, D. Wang, L. Wang, and Y. Ma, "Shapecontrolled synthesis of $3 \mathrm{D}$ hierarchical $\mathrm{MnO}_{2}$ nanostructures for electrochemical supercapacitors," Crystal Growth and Design, vol. 9, no. 1, pp. 528-533, 2009.

[9] S. Chou, F. Cheng, and J. Chen, "Electrodeposition synthesis and electrochemical properties of nanostructured $\gamma-\mathrm{MnO}_{2}$ films," Journal of Power Sources, vol. 162, no. 1, pp. 727-734, 2006.

[10] P. Ragupathy, D. H. Park, G. Campet et al., "Remarkable capacity retention of nanostructured manganese oxide upon cycling as an electrode material for supercapacitor," Journal of Physical Chemistry C, vol. 113, no. 15, pp. 6303-6309, 2009.

[11] J. F. Perez-Benito, C. Arias, and E. Amat, "A kinetic study of the reduction of colloidal manganese dioxide by oxalic acid," Journal of Colloid and Interface Science, vol. 177, no. 2, pp. 288297, 1996.

[12] S. C. Pang and B. H. Wee, "Flexible thin-film electrochemical capacitor and method of fabrication thereof," Malaysia Patent, no. PI 20094040, 2009.

[13] C. C. Lin and H. W. Chen, "Coating manganese oxide onto graphite electrodes by immersion for electrochemical capacitors," Electrochimica Acta, vol. 54, no. 11, pp. 3073-3077, 2009. 
[14] J. K. Chang, M. T. Lee, C. W. Cheng et al., "Pseudocapacitive behavior of $\mathrm{Mn}$ oxide in aprotic 1-ethyl-3- methylimidazolium-dicyanamide ionic liquid," Journal of Materials Chemistry, vol. 19, no. 22, pp. 3732-3738, 2009.

[15] W. Wei, X. Cui, W. Chen, and D. G. Ivey, "Electrochemical cyclability mechanism for $\mathrm{MnO}_{2}$ electrodes utilized as electrochemical supercapacitors," Journal of Power Sources, vol. 186, no. 2, pp. 543-550, 2009.

[16] P. Simon and Y. Gogotsi, "Materials for electrochemical capacitors," Nature Materials, vol. 7, no. 11, pp. 845-854, 2008.

[17] D. Qu, "The ac impedance studies for porous $\mathrm{MnO}_{2}$ cathode by means of modified transmission line model," Journal of Power Sources, vol. 102, no. 1-2, pp. 270-276, 2001.

[18] B. E. Conway, Electrochemical Supercapacitors. Scientific Fundamentals and Technological Applications, Klumer Academic/Plenum Publishers, New York, NY, USA, 1999.

[19] E. Beaudrouet, A. Le Gal La Salle, and D. Guyomard, "Nanostructured manganese dioxides: synthesis and properties as supercapacitor electrode materials," Electrochimica Acta, vol. 54, no. 4, pp. 1240-1248, 2009.

[20] H. Yagi, T. Ichikawa, A. Hirano, N. Imanishi, S. Ogawa, and Y. Takeda, "Electrode characteristics of manganese oxides prepared by reduction method," Solid State Ionics, vol. 154155, pp. 273-278, 2002.

[21] E. Barsoukov, "Electrochemical power sources-batteries," in Impedance Spectroscopy Theory, Experiment, and Applications, E. Barsoukov and J. R. Macdonald, Eds., chapter 4, John Wiley and Sons, New Jersey, NJ, USA, 2nd edition, 2005.

[22] S. E. Chun, S. I. Pyun, and G. J. Lee, "A study on mechanism of charging/discharging at amorphous manganese oxide electrode in $0.1 \mathrm{M} \mathrm{Na}_{2} \mathrm{SO}_{4}$ solution," Electrochimica Acta, vol. 51, no. 28, pp. 6479-6486, 2006.

[23] C. Xu, C. Wei, B. Li, F. Kang, and Z. Guan, "Charge storage mechanism of manganese dioxide for capacitor application: effect of the mild electrolytes containing alkaline and alkalineearth metal cations," Journal of Power Sources, vol. 196, no. 18, pp. 7854-7859, 2011.

[24] W. Lajnef, J. M. Vinassa, O. Briat, S. Azzopardi, and E. Woirgard, "Characterization methods and modelling of ultracapacitors for use as peak power sources," Journal of Power Sources, vol. 168, no. 2, pp. 553-560, 2007.

[25] A. J. Roberts and R. C. T. Slade, "Effect of specific surface area on capacitance in asymmetric carbon $/ \alpha-\mathrm{MnO}_{2}$ supercapacitors," Electrochimica Acta, vol. 55, no. 25, pp. 7460-7469, 2010.

[26] S. C. Pang, W. H. Khoh, and S. F. Chin, "Nanoparticulate magnetite thin films as electrode materials for the fabrication of electrochemical capacitors," Journal of Materials Science, vol. 45, no. 20, pp. 5598-5604, 2010.

[27] M. Toupin, T. Brousse, and D. Bélanger, "Influence of microstucture on the charge storage properties of chemically synthesized manganese dioxide," Chemistry of Materials, vol. 14, no. 9, pp. 3946-3952, 2002.

[28] M. Toupin, T. Brousse, and D. Bélanger, "Charge storage mechanism of $\mathrm{MnO}_{2}$ electrode used in aqueous electrochemical capacitor," Chemistry of Materials, vol. 16, no. 16, pp. 31843190, 2004.

[29] Q. Huang, X. Wang, and J. Li, "Characterization and performance of hydrous manganese oxide prepared by electrochemical method and its application for supercapacitors," Electrochimica Acta, vol. 52, no. 4, pp. 1758-1762, 2006.

[30] V. Subramanian, H. Zhu, and B. Wei, "Nanostructured $\mathrm{MnO}_{2}$ : hydrothermal synthesis and electrochemical properties as a supercapacitor electrode material," Journal of Power Sources, vol. 159, no. 1, pp. 361-364, 2006.
[31] K. R. Prasad and N. Miura, "Potentiodynamically deposited nanostructured manganese dioxide as electrode material for electrochemical redox supercapacitors," Journal of Power Sources, vol. 135, no. 1-2, pp. 354-360, 2004.

[32] J. K. Chang, C. H. Huang, W. T. Tsai, M. J. Deng, I. W. Sun, and P. Y. Chen, "Manganese films electrodeposited at different potentials and temperatures in ionic liquid and their application as electrode materials for supercapacitors," Electrochimica Acta, vol. 53, no. 13, pp. 4447-4453, 2008.

[33] A. Zolfaghari, F. Ataherian, M. Ghaemi, and A. Gholami, "Capacitive behavior of nanostructured $\mathrm{MnO}_{2}$ prepared by sonochemistry method," Electrochimica Acta, vol. 52, no. 8, pp. 2806-2814, 2007.

[34] R. Chandrasekaran, M. Koh, A. Yamauchi, and M. Ishikawa, "Electrochemical cell studies based on non-aqueous magnesium electrolyte for electric double layer capacitor applications," Journal of Power Sources, vol. 195, no. 2, pp. 662-666, 2010.

[35] S. Wen, J. W. Lee, I. H. Yeo, J. Park, and S. I. Mho, "The role of cations of the electrolyte for the pseudocapacitive behavior of metal oxide electrodes, $\mathrm{MnO}_{2}$ and $\mathrm{RuO}_{2}$," Electrochimica Acta, vol. 50, no. 2-3, pp. 849-855, 2004.

[36] L. Athouël, F. Moser, R. Dugas, O. Crosnier, D. Bélanger, and T. Brousse, "Variation of the $\mathrm{MnO}_{2}$ birnessite structure upon charge/discharge in an electrochemical supercapacitor electrode in aqueous $\mathrm{Na}_{2} \mathrm{SO}_{4}$ electrolyte," Journal of Physical Chemistry C, vol. 112, no. 18, pp. 7270-7277, 2008.

[37] C. Xu, B. Li, H. Du, F. Kang, and Y. Zeng, "Supercapacitive studies on amorphous $\mathrm{MnO}_{2}$ in mild solutions," Journal of Power Sources, vol. 184, no. 2, pp. 691-694, 2008. 


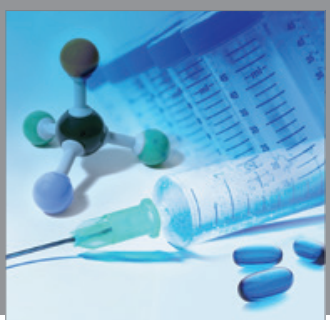

International Journal of

Medicinal Chemistry

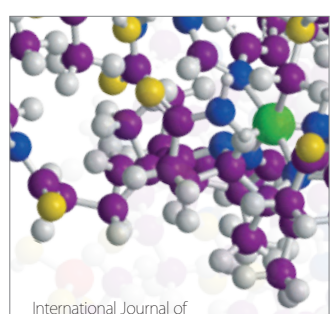

Carbohydrate Chemistry

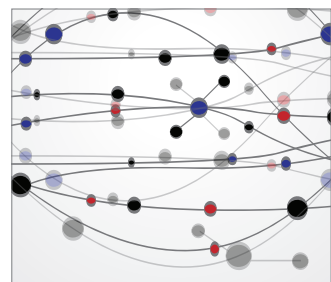

The Scientific World Journal
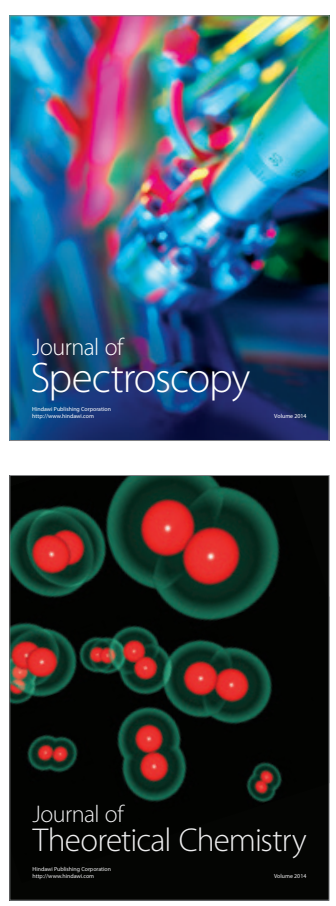
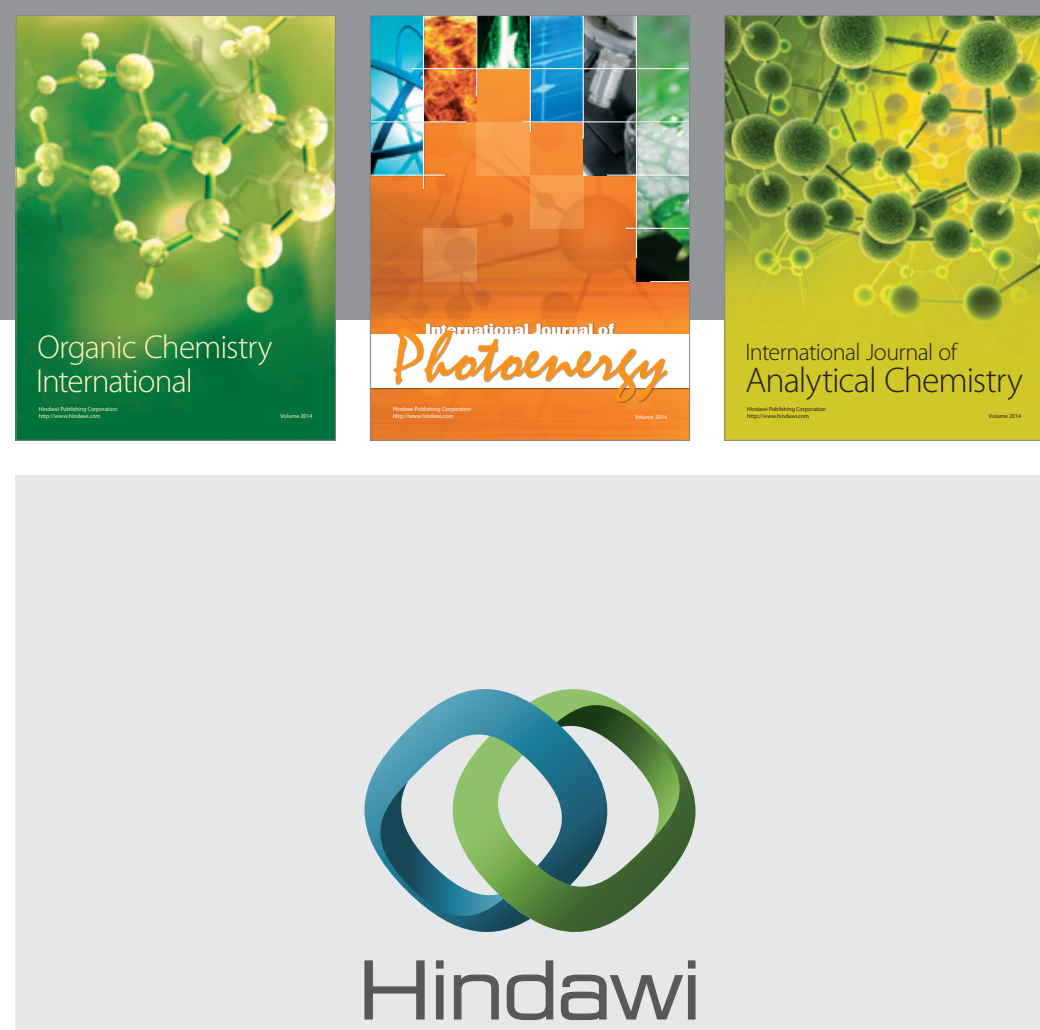

Submit your manuscripts at

http://www.hindawi.com
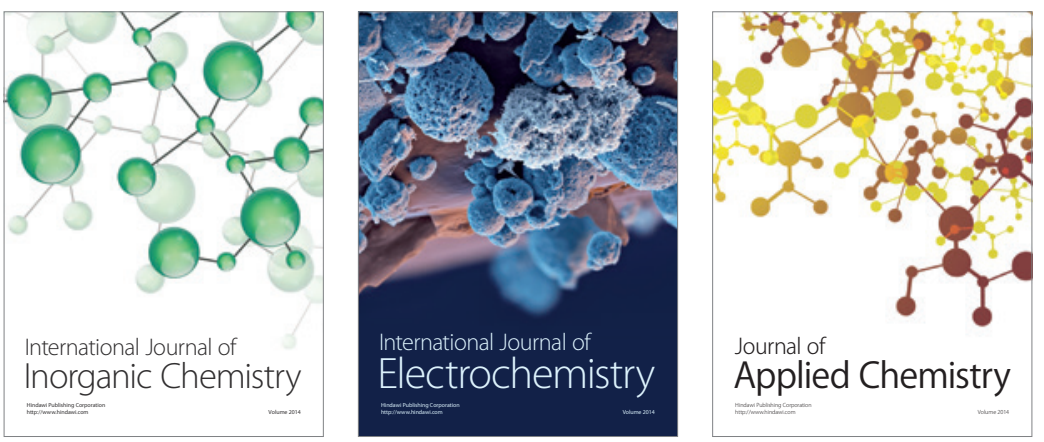

Journal of

Applied Chemistry
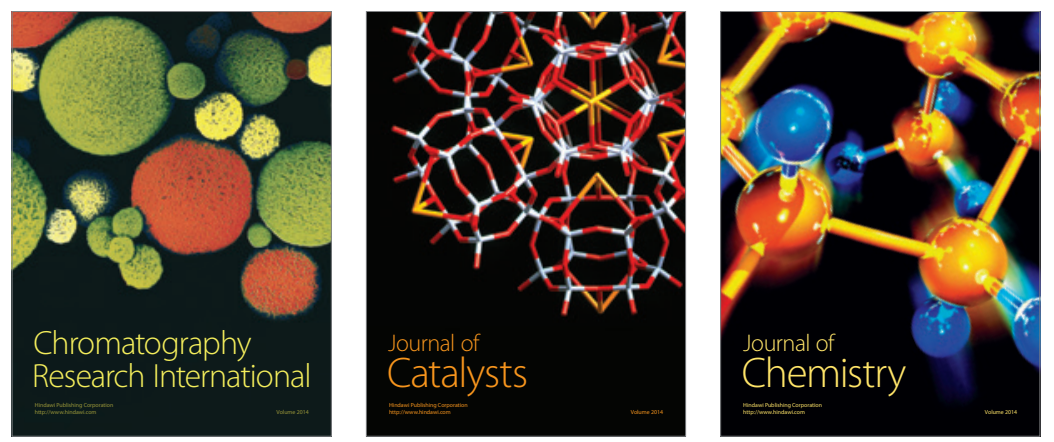
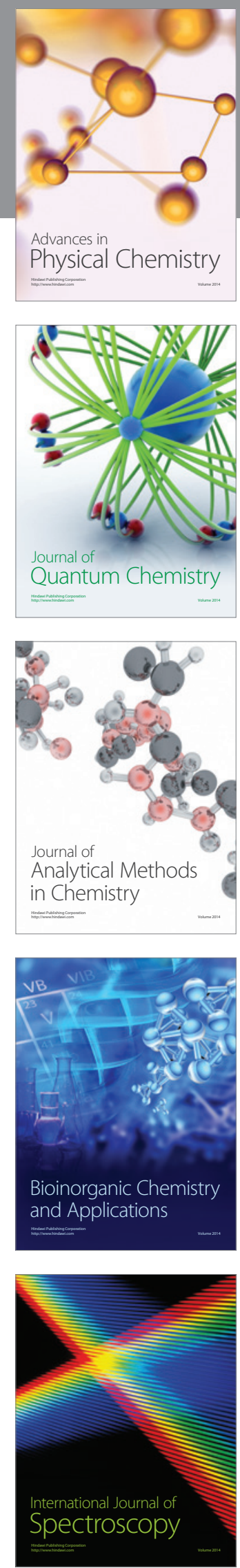